Supporting information/Experimental details

Partial Fluorination Overcomes Herringbone Crystal Packing in Small

\title{
Polycyclic Aromatics
}

Don M. Cho, Sean R. Parkin, and Mark D. Watson*

Dept. of Chemistry, University of Kentucky, Lexington, KY 40506-0055 USA

mdwatson@uky.edu/dcho@uky.edu

Materials and Methods. 2-Tributylstannyl thiophene and 2- $n$-hexyl thiophene (Aldrich), 1,2-diiodotetrafluorobenzene (Apollo Scientific), $\mathrm{Pd}\left(\mathrm{PPh}_{3}\right)_{4} \quad$ (Strem) were used as purchased. $\mathrm{C}_{6} \mathrm{~F}_{6}$, Toluene, ether, and THF were distilled from the appropriate drying agents and stored over molecular sieves. Compound $\mathbf{2 c}^{1}$ was prepared analogously to $\mathbf{2 a}$ below strictly for comparison of crystal packing, without further characterization. Unless otherwise stated, all manipulations and reactions were carried out under argon atmosphere using standard Schlenk techniques. High-resolution electron impact (EI) ionization mass spectra were recorded at $25 \mathrm{eV}$ on a JEOL JMS-700T MStation (magnetic sector instrument) at a resolution of greater than 10000. Samples were introduced via heatable direct probe inlet. Perfluorokerosene (pfk) was used to produce reference masses. We gratefully acknowledge the Mass Spectrometry Facility at the University of Kentucky for high-resolution mass spectra. ${ }^{1} \mathrm{H},{ }^{13} \mathrm{C}$, and ${ }^{19} \mathrm{~F}$ NMR spectra were recorded on a Varian INOVA $400 \mathrm{MHz}$ spectrometer (purchased under the CRIF Program of the National Science Foundation, grant CHE-9974810). Chemical shifts were referenced to solvent signals, except for ${ }^{19} \mathrm{~F}$ spectra, where $\mathrm{CCl}_{3} \mathrm{~F}$ was added as internal standard and set to $\delta=0.0 \mathrm{ppm}$. Photocyclizations were conducted in a Rayonet photochemical reactor equipped with $300 \mathrm{~nm}$ lamps and magnetic stirring.

\section{Synthetic procedures.}
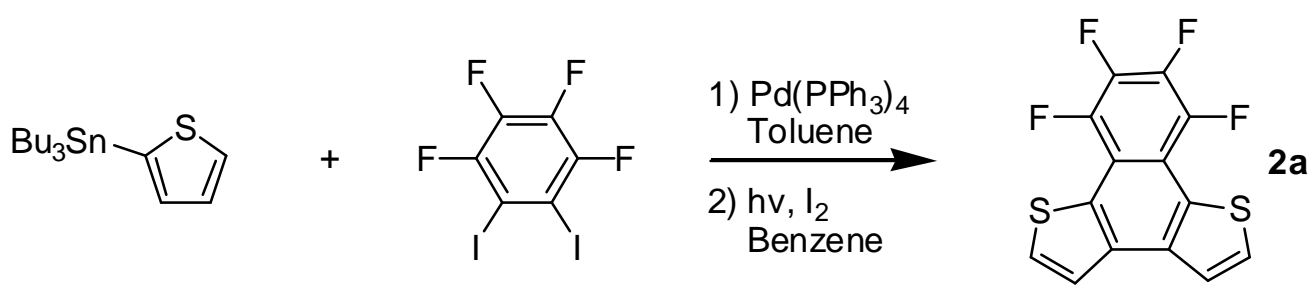

Compound 2a. In an oven dried vacuum flask, 1,2-diiodotetrafluorobenzene (2g, 4.98mmol), 2-tributylstannyl thiophene (3.9g, 10.45mmol), $\mathrm{Pd}\left(\mathrm{PPh}_{3}\right)_{4}(0.287 \mathrm{~g}, 5 \mathrm{~mol} \%)$ and $11 \mathrm{~mL}$ dry toluene were combined. The solution was sparged with argon, the flask was sealed, and then heated to $150^{\circ} \mathrm{C}$ for 12 hours. The solvent was then removed through rotary evaporation and the remaining non-volatiles run through a pad of silica with hexane to yield colorless microcrystals (1.44g, 4.75mmol, 92\%yield). 20mg $(0.064 \mathrm{mmol})$ of this product was then placed in a quartz tube with $6 \mathrm{~mL}$ of benzene and $\mathrm{I}_{2}(0.8 \mathrm{mg}, 5 \mathrm{~mol} \%)$. This was then irradiated ${ }^{2}$ for 30 minutes in an air atmosphere. Solvents were removed and the product was recrystallized from hexane to yield a white solid $(17 \mathrm{mg}, 86 \%)$. mp $239^{\circ} \mathrm{C} .{ }^{1} \mathrm{H}$ NMR $\left(\mathrm{C}_{6} \mathrm{D}_{6}\right) \delta: 7.22(\mathrm{~m}, 2 \mathrm{H}), 7.08(\mathrm{~d}, 2 \mathrm{H}, \mathrm{J}=4.8 \mathrm{~Hz})$ ${ }^{13} \mathrm{C} \mathrm{NMR}\left(\mathrm{CDCl}_{3}, 40^{\circ} \mathrm{C}\right) \delta: 154.35,144.90\left(\mathrm{dm},{ }^{1} \mathrm{~J}_{\mathrm{D}}=122 \mathrm{~Hz}\right), 139.93\left(\mathrm{dm},{ }^{1} \mathrm{~J}_{\mathrm{D}}=233 \mathrm{~Hz}\right)$, 131.34, 130.65, 127.98, 125.42. ${ }^{19} \mathrm{~F}$ NMR $\left(\mathrm{C}_{6} \mathrm{D}_{6}\right) \delta:-138.06,-155.95$. HR-MS: $311.9694+/-0.0005$ (1.6ppm) versus a calculated value of 311.9691 , error is 0.0003 (0.8ppm).

\footnotetext{
${ }^{1}$ Desai, H.S.; Tilak, B.D. J. Sci. Ind. Res. 1961, 20B, 22-30.

${ }^{2}$ Richard Kellogg, M.B. Groen, and Hans Wynberg. J. Org. Chem. 1967; 32: 3093-3100
} 
Supporting information/Experimental details

SI 2 of 2

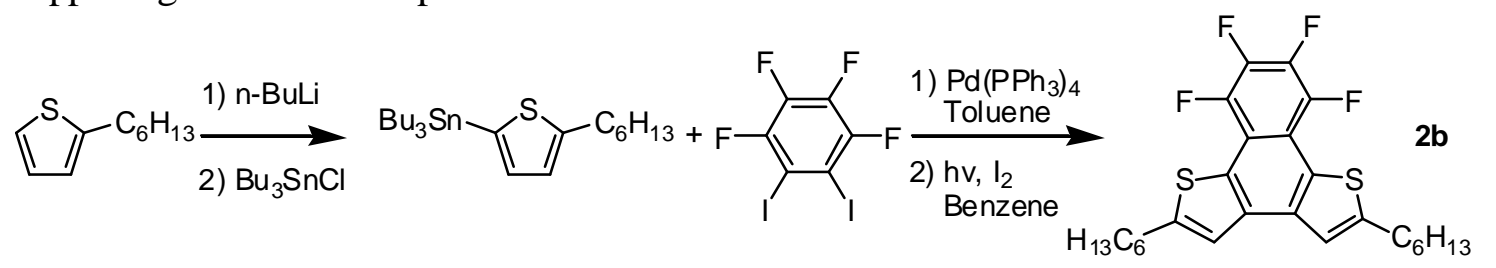

Compound 2b. In an oven dried Schlenk flask, n-butyl lithium (1.94 mL, 1.6M in hexanes) was added dropwise to $2-n$-hexyl thiophene $(0.523 \mathrm{~g}, 3.1 \mathrm{mmol})$ dissolved in $5 \mathrm{~mL}$ dry $\mathrm{THF}$ while cooling to $-25^{\circ} \mathrm{C}$. After stirring for $45 \mathrm{~min}$, But $3 \mathrm{SnCl}(1.01 \mathrm{~g}$, $3.1 \mathrm{mmol}$ ) was added dropwise and the solution was brought to room temperature and stirred for one hour. The mixture was then diluted with $\mathrm{MeCl}_{2}$ and washed with saturated $\mathrm{NH}_{4} \mathrm{Cl}$ (aq) and water, dried over $\mathrm{MgSO}_{4}$, and concentrated using rotary evaporation to yield a brown oil which was used without further purification $(1.29 \mathrm{~g}, 2.8 \mathrm{mmol}, 90 \%)^{3}$. This product was combined with 1,2-diiodotetrafluorobenzene $(0.5 \mathrm{~g}, 1.2 \mathrm{mmol}), 5 \mathrm{~mL}$ dry toluene, and $\mathrm{Pd}\left(\mathrm{PPh}_{3}\right)_{4}(72 \mathrm{mg}, 5 \mathrm{~mol} \%)$ in an oven dried vacuum flask. The flask was deaerated for 5 minutes with argon, sealed, and brought to $150^{\circ} \mathrm{C}$ for $12 \mathrm{hr}$. The solvent was removed by rotary evaporation and the nonvolatiles run through a column of silica gel with hexanes to yield a colorless oil $(0.55 \mathrm{~g}, 92 \%)$. 20mg $(0.042 \mathrm{mmol})$ of this product was then placed in a quartz tube with $6 \mathrm{~mL}$ benzene and $\mathrm{I}_{2}(0.5 \mathrm{mg}, 5 \mathrm{~mol} \%)$ and irradiated for 30 minutes in an air atmosphere. Solvents were removed and the product was recrystallized from boiling ethanol to yield a white solid $(16 \mathrm{mg}, 79 \%) \mathrm{mp} 86.5^{\circ} \mathrm{C}$.

${ }^{1} \mathrm{H}$ NMR $\left(\mathrm{C}_{6} \mathrm{D}_{6}\right) \delta: 7.20(\mathrm{~s}, 2 \mathrm{H}), 2.807(\mathrm{t}, 4 \mathrm{H}), 1.71(\mathrm{p}, 4 \mathrm{H}), 1.30(\mathrm{~m}, 12 \mathrm{H}), 0.91(\mathrm{t}, 6 \mathrm{H})$ ${ }^{13} \mathrm{C} \mathrm{NMR}\left(\mathrm{CDCl}_{3}\right) \delta: 149.60(\mathrm{~m}), 142.34\left(\mathrm{dm}{ }^{1} \mathrm{~J}_{\mathrm{d}}=249.3 \mathrm{~Hz}\right), 137.46\left(\mathrm{dm} 138.70{ }^{1} \mathrm{~J}_{\mathrm{d}}=171\right.$ $\mathrm{Hz}), 134.541,126.143,118.52,112.82$ (m), 31.58, 30.52, 29.02, 28.81, 22.57, 14.14. ${ }^{19} \mathrm{~F}$ NMR $\left(\mathrm{C}_{6} \mathrm{D}_{6}\right) \delta$ : $-138.71,-156.96 . \quad$ HR-MS: $480.1574+/-0.0006$ (1.2ppm), versus a calculated value of 480.1569 , error is 0.0005 (1.0ppm).
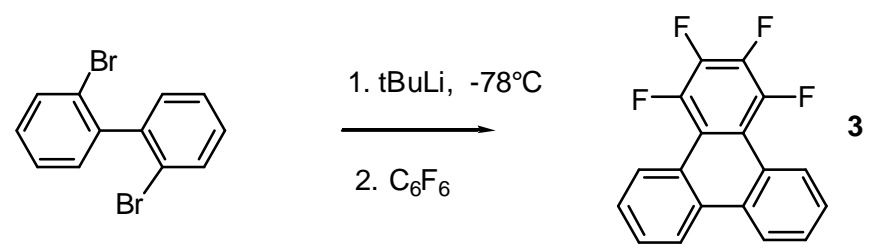

Compound 3. $t$-BuLi $(7.0 \mathrm{~mL}$ of a $1.65 \mathrm{M}$ solution in hexanes, $4 \mathrm{eq})$ was slowly added via syringe to 2,2'-dibromobiphenyl $(0.90 \mathrm{~g}, 2.9 \mathrm{mmol})$ in $60 \mathrm{~mL}$ dry ether, while maintaining the temperature below ${ }^{-} 70^{\circ} \mathrm{C}$. After allowing the solution to slowly warm to RT over 3 hours, $\mathrm{C}_{6} \mathrm{~F}_{6}(0.50 \mathrm{~mL}, 1.5 \mathrm{eq})$ and $10 \mathrm{~mL}$ DME were added in rapid secession and the vessel was sealed. After 15 minutes, copious precipitate had formed and GC-MS indicated $\sim 90 \%$ conversion. After stirring overnight, the mixture was stirred vigorously with $10 \% \mathrm{HCl}(\mathrm{aq})(2 \times 50 \mathrm{~mL})$. Volatiles were evaporated under reduced pressure and the remaining solid was washed repeatedly with pentane. The pale tan solid was $>98 \%$ pure by GC-MS $(0.610 \mathrm{~g}, 68 \%$ yield). An analytical sample was prepared by recrystallization from hot $\mathrm{CHCl}_{3} .{ }^{1} \mathrm{H} \mathrm{NMR}\left(\mathrm{CDCl}_{3}, 58^{\circ} \mathrm{C}\right) \delta: 8.89(\mathrm{~m}, 2 \mathrm{H}), 8.60(\mathrm{~m}$, 2H), $7.68(\mathrm{~m}, 2 \mathrm{H}), 7.63(\mathrm{~m}, 2 \mathrm{H})){ }^{19} \mathrm{~F}$ NMR $\left(\mathrm{CDCl}_{3}, 58^{\circ} \mathrm{C}\right) \delta:-138.62,-158.07$. HR-MS: $300.0562+/-0.0004(1.5 \mathrm{ppm})$ versus a calculated value of 300.0562 , error is 0.0000 (0.0ppm)

${ }^{3}$ J. Roncali, P. Blanchard, et al. Chem. Eur. J. 2003, 9, 5297-5306 